\title{
Takashiro Akitsu: Environmental Science: Society, Nature, and Technology
}

Ken Jones ${ }^{1}$

(c) Springer-Verlag GmbH Germany, part of Springer Nature 2019
50 years ago blackboard and chalk was the common interface of learning, slowly superseded by slides and projectors, but now that most data are produced directly from instruments or other computer-based devices the evolution to e-learning is now complete.

What cannot be judged from reviewing this book is how effective the 'old' compares to the 'new'. Are the questions raised (Active Learning) sufficiently searching to challenge the student? Are the contents of the Powerpoint ${ }^{\circledR}$ presentations sufficiently broad? How well researched is the content? Is there a linked continuity between subject matter?

It cannot be argued that this style of presentation is here to stay, but as always what matters more is the lecturer's personality, knowledge, enthusiasm and charisma in the subject matter. If these are present then the method and style of presentation becomes almost secondary. The content is clearly directed towards other academics rather than a broader readership, perhaps seeking better processes in presentation and content. Most aspects of the generalised subject of environmental sciences are covered, allowing any individual adopting the proposed format to add, subtract or emphasise whatever element they wish to express-and it assumed others will find it a useful framework for their lecture notes.

Publisher's Note Springer Nature remains neutral with regard to jurisdictional claims in published maps and institutional affiliations.

Ken Jones

chromatographia@springer.com

1 Knutsford, UK 